\title{
La Ruta de la Seda: entre el relato medieval, la novela histórica y los textos contemporáneos
}

\author{
The Silk Road: amongst medieval story, historical novel \\ and contemporary texts
}

Karolina Zygmunt

karolina.zygmunt12@gmail.com

Recibido: 21/03/2018. Aceptado: 11/06/2018

Resumen: El objetivo de este artículo es analizar algunas obras contemporáneas que recrean el mítico trayecto de la Ruta de la Seda y mencionan a los viajeros medievales que lo recorrieron. Se estudia en concreto cómo el relato de la Embajada a Tamorlán, una de las obras clave de la literatura de viajes medievales hispánicos, sirve de base y referente textual para la novela histórica de Fernando Martínez Laínez, Embajada a Samarcanda, e inspira a Miguel Silvestre, quien en su relato Emoción del nómada declara seguir las huellas de los embajadores medievales. Se analiza de qué forma estos textos contemporáneos, al establecer un diálogo con el relato medieval, ven condicionadas o transformadas de manera patente o implícita sus poéticas narrativas.

Palabras clave: Ruta de la Seda; Embajada a Tamorlán; Embajada a Samarcanda; Emoción del nómada; Ruy González de Clavijo.

\begin{abstract}
The aim of this article is to analyse some contemporary works that recreate the mythical path of the Silk Road and which make mention of the medieval travellers who crossed it. In particular, it will be studied how the travelogue Embajada a Tamorlán, one of the key works of hispanic medieval travel literature, influences two contemporary books. This medieval work serves as a basis and as textual reference for the historical novel by Fernando Martínez Laínez, Embajada a Samarcanda, and it inspires Miguel Silvestre, who in his travelogue Emoción del nómada declares to follow the tracks of the medieval ambassadors. In this article it is shown how the poetic narratives of these contemporary texts are conditioned or transformed, clearly or implicitly, by establishing a dialogue with the medieval story.
\end{abstract}

Keywords: The Silk Road; Embajada a Tamorlán; Embajada a Samarcanda; Emoción del nómada; Ruy González de Clavijo.

》) Zygmunt, Karolina. 2018. "La Ruta de la Seda: entre el relato medieval, la novela histórica y los textos contemporáneos". Quaderns de Filologia: Estudis Literaris XXIII: 63-78. doi: 10.7203/qdfed.23.13444 



\section{La Ruta de la Seda, guía de viajeros y generadora de sentidos}

Patricia Almarcegui, en su relato de viajes por Asia Central, comenta:

Quien ama el viaje sabe del poder que tienen los nombres. Hay lugares que solo con escucharlos o citarlos la imaginación explota y genera imágenes mágicas y sueños suspendidos (2016: 55)ํ.

Sin lugar a dudas, la Ruta de la Seda es uno de estos nombres. Los historiadores parecen estar de acuerdo en que la Ruta, más allá de la simple red de caminos que favorecían los intercambios de mercancías, constituía una importantísima vía de comunicación entre Oriente y Occidente. Pero, además, en torno a este "espacio cultural y humano" (De Bunes Ibarra, 2013: 14), se ha ido creando a lo largo de la historia una especie de gran mito. Lo cierto es que esta zona inquietante y seductora, escenario de sueños y pesadillas, ha ejercido una atracción innegable y se ha convertido en una fuente de inspiración para la creación literaria de muchas épocas. Y de la misma forma que los lugares y los personajes emblemáticos de la Ruta de la Seda despiertan el interés del público actual, también siguen presentes en el imaginario colectivo los relatos de quienes la recorrieron en el pasado.

Indudablemente, el Libro de las maravillas del mundo de Marco Polo ha ocupado por méritos propios un sitio privilegiado en la literatura de viajes sobre la Ruta de la Seda. La historia de este mercader veneciano, aunque criticada por todas las exageraciones y fantasías que introdujo el verdadero redactor del libro, Rustichello de Pisa, sigue siendo el referente por antonomasia dentro de este panorama ${ }^{2}$. No

\footnotetext{
* El presente trabajo se ha realizado gracias a la ayuda FPU14/01214 del Ministerio de Educación, Cultura y Deporte (actualmente el Ministerio de Ciencia, Innovación y Universidades), y forma parte del proyecto de investigación Parnaseo (Servidor Web de Literatura Española), FFI2017-82588-P (AEI/FEDER, UE), concedido por el Ministerio de Economía, Industria y Competitividad.

${ }^{1}$ Utilizo el término "relatos de viajes" de acuerdo con la propuesta de Luis Alburquerque, para, dentro de la categoría de literatura de viajes, hablar de textos factuales, testimonios de una experiencia vivida en oposición a los textos ficcionales centrados en el motivo del viaje. A estos últimos, siguiendo a Alburquerque, me referiré como "novelas de viaje". Para más información véase: Alburquerque García (2011) y Alburquerque García (2015).

${ }^{2}$ Luce Boulnois (2004), en el capítulo “¿Para qué sirve mentir cuando se viene de lejos?", presenta brevemente la polémica referente a la veracidad de la obra, así como
} 
obstante, si nos trasladamos al contexto español, cabe señalar el relato de la Embajada a Tamorlán, testimonio legado por escrito de la misión castellana a la corte del gran caudillo mongol Tamorlán. Y resulta que este antiguo texto hispánico, como evidencia fehaciente y singular que es, también alcanza al imaginario actual y funciona como un modelo y referente para los escritores contemporáneos. Así, Martínez Laínez, en su novela histórica Embajada a Samarcanda, se basa en el original medieval para crear su propia ficción literaria, mientras que Miguel Silvestre, en La emoción del nómada, declara seguir las huellas de Ruy González de Clavijo, uno de los embajadores medievales a la corte del gran Kan. Por consiguiente, se trata de tres textos de características diferentes, unidos por el mismo ámbito geográfico de la Ruta de la Seda y el diálogo que las obras actuales mantienen con el original medieval.

El análisis de la novela de Martínez Laínez (2003) y su comparación con el relato medieval serán el núcleo de este artículo, mientras que el texto más reciente de Silvestre (2013) servirá para indicar una tendencia nueva, ya posible de detectar en el panorama literario actual: la aparición explícita del ámbito de la Ruta de la Seda y la utilización de las figuras de los viajeros antiguos en los textos de escritores-viajeros contemporáneos.

\section{Embajada a Tamorlán: el relato del pasado que inspira el presente}

Antes de centrarnos en los textos actuales que revitalizan el relato de la Edad Media, resulta necesario acercarse a la obra original y situarla en su contexto histórico. A finales del XIV descuella en Oriente la figura de un poderoso caudillo militar turco-mongol, conocido por los castellanos como Tamorlán, Tamurbec o Amir Timur (1336-1405), conquistador de múltiples territorios, desde la India hasta Moscú, y creador de un impresionante imperio ${ }^{3}$. Como comenta Rodríguez Zahar, "a pesar de lo efímero de su imperio, Tamerlán logrará anclarse en el imaginario colectivo europeo" (Rodríguez Zahar, 2013: 53). Y esto se debe, entre otros motivos, al hecho de que con su victoria sobre los otomanos en

a las exageraciones e inexactitudes que aparecen en el relato. Para más, véase: Wood (1997).

${ }^{3}$ Tamorlán fue quien restableció el poder del cual gozaron los mongoles en el siglo XII con Gengis Kan. 
la batalla de Ankara, en 1402, los reyes europeos vieron en el caudillo mongol un posible aliado, con el que combatir el inminente peligro de los turcos, encerrándolos entre Oriente y Occidente. Como resume López Guzmán, la presencia en esta batalla de embajadores europeos hizo que su figura fuera conocida en Occidente "como la de un héroe, derivándose la posibilidad de alianzas contra los turcos" (López Guzmán, 2013: 62).

Por esta razón, la corte de Tamorlán se convirtió en el objetivo final de diversas misiones diplomáticas de monarcas cristianos, entre las que destacan las castellanas. Pelayo de Sotomayor y Fernando de Palazuelo fueron los primeros embajadores enviados por el rey Enrique III al gran Tamorlán y su primer viaje, en 1401, pudo considerarse un éxito ${ }^{4}$. Esperanzado por los buenos resultados de la primera misión, el rey decidió mandar una segunda embajada en la que participaron Ruy González de Clavijo, Páez de Santamaría y Gómez de Salazar. La comitiva, que partió en 1403, recorrería una gran parte de los territorios de la Ruta de la Seda llegando a Samarcanda, en aquella época capital del imperio mongol y residencia del Gran Kan. Aunque los embajadores no consiguieron sus objetivos ${ }^{5}$, esta misión es valorada por los historiadores como uno de los episodios más importantes de la diplomacia española de la Edad Media y probablemente "el único que ha llegado a universal conocimiento y que ha alcanzado verdadera difusión" (López Estrada, 2003: 66).

El testimonio principal y resultado literario de este significativo acontecimiento histórico es el relato pormenorizado del viaje, la llamada Embajada a Tamorlán, en escritura atribuida tradicionalmente a Ruy González de Clavijo ${ }^{6}$. La Embajada constituye probablemente, junto con las Andanças de Pero Tafur, el libro de viajes medievales castellanos más genuino y es considerado por López Guzmán como “un legado mucho más importante para la posteridad que una posible alianza

\footnotetext{
${ }^{4}$ Los emisarios fueron bien recibidos por el Kan y regresaron a Castilla acompañados por un embajador mongol, Mohamed Alcagi, y portando una carta de Tamorlán al rey Enrique III, así como diversos obsequios que permitían augurar un futuro de excelentes relaciones diplomáticas.

${ }^{5}$ No recibieron la esperada respuesta del Gran Kan, que murió menos de dos meses después de la llegada de los embajadores a Samarcanda.

${ }^{6}$ La autoría de Embajada a Tamorlán ha resultado una cuestión polémica, aunque actualmente la mayor parte de la crítica se inclina hacia una autoría colectiva. Esta idea la defienden, entre otros, Rubio Tovar (1986), Beltrán (1991) o Almarcegui (2013).
} 
política y militar imposible de concretar en aquel momento histórico" (López Guzmán, 2013: 75)7.

\section{Embajada a Samarcanda: entre la poética medieval y el texto contemporáneo}

Pero incluso hoy en día podemos hablar de las huellas de Embajada a Tamorlán dentro de un panorama literario en el que resulta tan insólita como sintomática la presencia de textos que se refieren explícitamente a este original medieval. En efecto, la novela histórica de Fernando Martínez Laínez, Embajada a Samarcanda, reescribe la experiencia de la famosa embajada ${ }^{8}$. El texto cuenta la historia de Laura, una profesora de Historia Medieval que durante su viaje a Estambul compra un antiguo manuscrito escrito en castellano. Serán nada menos que los apuntes personales de Ruy González de Clavijo que en el siglo XV acabaron en Constantinopla porque su circulación en España estaba prohibida por el rey. Laura se sumergirá en la lectura conociendo los detalles nuevos de la famosa misión histórica, pero finalmente el manuscrito será robado y así se perderá para siempre la única y verdadera historia de la embajada española ante Tamorlán.

El autor de la obra, Martínez Laínez, es un periodista, especializado en asuntos internacionales, polígrafo ensayista, consolidado y bien considerado en el campo literario contemporáneo, y la novela histórica constituye uno de sus géneros predilectos. Aunque en sus declaraciones en torno al proceso de concepción y escritura de esta obra, insiste en la libertad del escritor a la hora de crear ficción literaria, comenta al mismo tiempo que su novela fue el resultado de una profunda indagación histórica previa. La lectura de la obra lo confirma. El hondo conocimiento del texto de la Embajada y la investigación sobre los contextos que demuestra el autor de la versión moderna son incuestionables y lo pueden confirmar diferentes episodios presentes en el original que se

\footnotetext{
${ }^{7} \mathrm{El}$ mundo académico ha mostrado un interés especial hacia este texto. Junto a los trabajos sobre la Embajada de López Estrada (entre los más recientes, 1999, 2003, 2004, 2005), destacan los de Pérez Priego (1984), Rubio Tovar (1986), Beltrán (1991), Carrizo Rueda (1997), Béguelin-Argimón (2011) o Almarcegui (2013). Asimismo, cabe destacar el estudio de Juan Gil (1993) y la edición del texto a cargo de Ramón Alba (1984). ${ }^{8}$ La novela se inscribe dentro de lo que podríamos llamar el boom de la novela histórica de tema medieval. Para más información, véase: Huertas Morales (2012).
} 
repiten en el relato contemporáneo. Martínez Laínez, por otra parte, intenta emular determinados recursos retóricos y aspectos del estilo del hipotexto, esforzándose en conservar el lenguaje de la época y reflejar la mentalidad medieval.

Entre otras estrategias narrativas, Martínez Laínez se sirve del recurso del manuscrito encontrado para introducir temas inexistentes en el original. De esta forma, la embajada a la corte de Tamorlán constituye el hilo fundamental del relato, pero no es el único tema de la obra. Se podría decir que el escritor crea la versión contemporánea de esta historia de pasado - una especie de reflejo o desdoblamiento en el tiempo-, lo que resulta especialmente interesante, ya que pone de relieve la tensión visible en el acto de escribir sobre el tema medieval, pero desde una perspectiva inevitablemente contemporánea. Por esta razón el texto en muchos de sus rasgos seguirá fielmente la gramática interna del relato medieval de viaje, pero en otros muchos se alejará de ella desarrollando estrategias retóricas típicamente contemporáneas.

El interés en reproducir con la máxima fidelidad la manera medieval de narrar se observa especialmente en las descripciones de ciudades desconocidas, que se asemejan inconfundiblemente al modelo original. Del mismo modo, en la descripción de los animales exóticos -el elefante, la jirafa-, tan peculiar en el libro de viajes antiguos, Martínez Laínez sigue fiel el esquema descriptivo del texto medieval: "la jornusa o jirafa, el cual animal tenía el cuerpo tan grande como un caballo, el pescuezo muy luengo [...] y el pie hendido como de buey" (2003: 167)'. Asimismo, en la novela se mantienen y potencian las comparaciones de la realidad nueva con lo previamente conocido, bien características de los textos de relatos medievales, utilizando ciudades como, por ejemplo, Sevilla como punto de referencia y apoyo: "Constantinopla y Pera son como Sevilla y Triana, con el puerto en el Guadalquivir y los navíos en medio" (Martínez Laínez, 2003: 238). En este y muchos más fragmentos Martínez Laínez parece parafrasear apenas -casi copiar-el texto en el que se basa ${ }^{10}$.

El escritor contemporáneo busca reflejar el saber y las creencias de la época y aprovecha el texto base de la Embajada, pero añade nuevos

\footnotetext{
${ }^{9}$ Para más información sobre la descripción de los animales exóticos en los relatos medievales de viaje y en la novela histórica, véase: Zygmunt (2016).

${ }^{10}$ El original medieval: "Constantinopla está así como Sevilla, e la ciudat de Pera, así como Triana; e el puerto e los nabíos, en medio" (1999: 144).
} 
elementos de su cosecha al comentar, por ejemplo, algunas creencias populares relacionadas con el Arca de Noé. De igual modo, la mentalidad medieval se ve reflejada en ideas básicas como las que giran en torno a los caprichos de la fortuna y la convicción de que las buenas obras garantizan la vida eterna: "el favor de la Fortuna sube y baja [...], nada ha de servirnos en la otra vida sino nuestras buenas obras y la fe en Dios" (Martínez Laínez, 2003: 138-139). Introduce como elementos destacados las creencias medicinales de la época, por otra parte bien documentadas, como la sangría con sanguijuelas para relajarle los humores al rey, lo que se relaciona directamente con la teoría de los humores de la Edad Media. Y, así, en el comentario sobre el terror que sentía Gengis Kan ante la muerte, se puede apreciar cómo su postura recrea el tópico medieval de la danse macabre, la falsa muerte democrática o final que se lleva a todos por igual, sin distinguir estatus ni condición:

¿De qué sirve todo mi poder -se quejaba- si al final he de morir como cualquiera de mis enemigos? Los golpes de la muerte son iguales a las patadas de un camello ciego; el hombre alcanzado entrega su alma (Martínez Laínez, 2003: 323-324).

Comentando las creencias de la época medieval, resulta imposible no mencionar la presencia de lo maravilloso, otro elemento típico de la poética de viaje medieval que utiliza como variación llamativa y exótica el escritor contemporáneo. En la novela de la Embajada a Samarcanda se mencionan, entre otros, unos monstruos marinos muy temidos por los marineros que no aparecen en el texto medieval de base, aunque sí en otros libros de viajes, como los de Mandeville, o en los bestiarios más conocidos. Y un tipo específico de lo maravilloso será el milagro divino. En la obra de Laínez se repiten muchos de los milagros recogidos en el original medieval, pero también aparecen otros que no se mencionan en el texto modelo, como es el caso del milagro del cuerpo de Santo Tomé. El texto de Laínez, por otro lado, se mantiene fiel al original medieval al comentar pormenorizadamente las visitas a las numerosas iglesias y monasterios -en especial, en Constantinopla- y la posibilidad de admirar diferentes reliquias.

Junto a la descripción minuciosa de ciudades y animales exóticos, la presencia tangible de lo maravilloso y la importancia de la religión, entre las características medievales del relato de viaje que incorpora Martínez Laínez cabría destacar toda una serie de referencias históricas 
y mitológicas. La alusión al conflicto troyano, presente en Embajada a Tamorlán, es recogida e imitada también en la novela histórica, en la que además se comentan, entre otros episodios, a modo de amplificación, historias o leyendas, como de la espada de los hunos o la relación de Atila con su última esposa, Ildico.

Finalmente, la Embajada a Samarcanda contemporánea, fiel a los contextos del viaje original, presenta el itinerario de los embajadores como un trayecto repleto de peligros y menciona las mismas penurias y tormentos que aparecen en el texto medieval. Insiste en distintas ocasiones en la falta de seguridad durante el camino y reflexiona sobre la necesidad de cambiar de ruta por el peligro que en muchos casos habría supuesto seguir los planes iniciales.

Todos estos rasgos nos hacen ver que el autor ha intentado mantenerse lo más fiel posible a la poética de los relatos medievales de viajes, reflejando en su obra las características propias de los textos legados por los viajeros del pasado. No obstante, tal y como se ha mencionado, su perspectiva es inevitablemente contemporánea y su trabajo está condicionado por los dictámenes marcados tanto por unos nuevos receptores (los lectores actuales) como por unas nuevas relaciones en el mercado del libro. La ficción que crea es, por un lado, una historia ambientada en la Edad Media, basada en hechos reales y documentada con fuentes históricas, pero por otra parte tiene que ser una ficción amena que cumpla con una nuevas convenciones narrativas e interese a un público relativamente amplio, tratando de ocupar un espacio en el mundo editorial. Por esta razón, Embajada a Samarcanda ha de incorporar forzosamente rasgos inexistentes en los textos medievales, que la ubiquen de manera armónica, sin estridencias de códigos cifrados incomprensibles, en la escena literaria contemporánea.

Tal vez la diferencia clave que separe esta novela histórica de su original medieval sea el planteamiento nuevo de una subjetividad moderna para el protagonista y relator del viaje. Mientras que en la Embajada a Tamorlán medieval a lo largo de todo el relato se intenta mantener una mirada objetiva sobre la realidad vista, la obra de Martínez Laínez se construye y adereza a través de las muy frecuentes opiniones personales del protagonista medieval. El relato antiguo no puede profundizar en la interioridad del personaje o personajes viajeros, puesto que quien realiza el viaje no es importante, sino que es el propio viaje -el colectivo al servicio de la misión diplomática- el centro de la atención. En cambio, 
en la novela actual se puede observar la preocupación por reflejar la personalidad de Clavijo, mostrar sus inquietudes y su forma de entender el mundo. El carácter reflexivo del protagonista se va cimentando a lo largo de todo el texto, puesto que la descripción de los hechos vividos se ve complementada por sus divagaciones constantes sobre, entre otros, los sentimientos del monarca y su carácter, el comportamiento de otros personajes cercanos a la corte y la naturaleza humana en general. El propio Clavijo se entretiene introspectivamente en el análisis autobiográfico:

Desde joven he sentido luchar dentro de mi ánimo varias fuerzas. El deseo de vivir quieto y asosegado, al amor de la lumbre, cuidando de mi casa y familia, junto con el ansia de ver otras tierras y gentes y participar de las cosas del mundo (Martínez Laínez, 2003: 177).

En una estrecha relación con esta subjetividad del protagonista, aparece otra característica nueva: la manifestación del tema amoroso (con su lenguaje sentimental) y con él, del conflicto entre lo público y lo privado. La historia de amor de Clavijo y Constanza - desde luego ausente en el original medieval- constituye uno de los núcleos de Embajada a Samarcanda. Ya en uno de los primeros folios de su manuscrito el protagonista comenta el gran amor que siente por Constanza, la hermana de León de Armenia, con la que se supone que mantuvo una relación antes de que la dama abandonara Castilla. El compromiso amoroso provocará un conflicto entre lo personal y lo político, obligando al protagonista a decidir qué dimensión de su vida resulta más importante. La dicotomía no está planteada de manera tan simple como pudiera parecer, puesto que el viaje a Samarcanda, con su misión política como camarero en la corte, de alguna forma supone la realización o cumplimiento de unos sueños personales, pero compartidos: los de alcanzar a ver las tierras de las que tanto le había hablado su amada.

Las historias amorosas de los protagonistas tienen como objetivo llamar la atención del lector, haciendo más atractivo y variado, con nuevos ingredientes, el contenido de la obra con su itinerario viajero. La misma función cumplirá la introducción de los elementos de intriga y misterio, propios del género de aventuras. Aunque Martínez Laínez está muy limitado en su creación, ya que sigue con la fidelidad esencial que hemos comentado el texto medieval original, la introducción de estos elementos nuevos le permite dotar a su novela de una tensión narrativa inexistente en el hipotexto del que se parte. 


\section{La emoción del nómada: un motero contemporáneo siguiendo huellas de viajes remotos}

Martínez Laínez no es el único que ambienta su obra en los territorios de la famosa Ruta de la Seda. En el panorama literario actual podemos hablar de una serie de textos cuyos autores deciden recorrer este camino mítico y poner por escrito su experiencia. En este contexto cabría destacar a Patricia Almarcegui, con Una viajera por Asia Central (2016), a Pablo Strubell con Te odio, Marco Polo (2009), a Carlos Martínez de Campos, con Caballos alados de la ruta de la seda (2000), a Bernard Ollivier, con La ruta de la seda. Viaje en solitario (2005), y, finalmente, a Miguel Silvestre, autor de La emoción del nómada (2013) y Nómada en Samarcanda (2016). Este último, tal y como comenta Peñate (2015), no duda en reconocer que en su viaje sigue las huellas de Ruy González de Clavijo.

A diferencia de Martínez Laínez, en el caso de Silvestre no estamos hablando de un escritor profesional, consolidado en el panorama literario actual y conocido por sus obras en un género concreto. Él es - confiesa- un funcionario (registrador de la propiedad) que aprovecha los permisos laborales para viajar por el mundo y describir sus experiencias. No obstante, como ha subrayado en múltiples ocasiones, está interesado desde luego en la escritura y tiene más que suficiente experiencia en el mundo literario ${ }^{11}$. De hecho, le gusta hablar de sí mismo como escritor y declara su voluntad de convertirse en escritor profesional de libros de viajes. De manera que durante su recorrido no solo prepara las notas para su futuro libro, sino que también manda algunas de sus historias a varios periódicos, conectando de esta forma con la figura clásica del viajero-periodista de los siglos XIX, XX y XXI.

La obra de Silvestre, a diferencia de la novela de Martínez Laínez, que pertenece evidentemente a la ficción literaria, es un testimonio del viaje real que el autor realizó en moto por Asia Central en un año de excedencia de su trabajo. Por lo tanto puede ser considerada un relato de viaje, como lo es la historia de los embajadores de Enrique III a Tamorlán. Por esta razón, la relación que La emoción del nómada

\footnotetext{
${ }^{11}$ Sus obras, antes de haber publicado La emoción del nómada (2013), eran, entre otras, Mariposas en el cuarto oscuro (2003), La dama ciega (2005) y Spanya SA (2008), así como la colección de relatos Dinamo estrellada (2004), todas ellas publicadas en Ediciones Barataria.
} 
establece con el original medieval es necesariamente muy distinta que la que evidencia la Embajada a Samarcanda. En el texto de Silvestre la única perspectiva posible es la contemporánea. El autor en ningún momento busca crear una ambientación medieval ni acercar al lector a la gramática interna o a la poética de los relatos de viajes medievales. El estilo del texto y sus características lo ubican exclusivamente en el contexto socio-histórico y literario actual. El protagonista-escritor se centra, sobre todo, en su experiencia y sus sensaciones en pleno siglo XXI. Se trata de un viaje marcado por las valoraciones personales, en el que destaca un claro predominio del "yo" sobre el "nosotros", del individuo frente al colectivo y de la subjetividad moderna frente al esfuerzo medieval por la objetividad.

El único gesto que podríamos denominar "medieval" que hace Silvestre es recorrer los mismos territorios que los embajadores españoles y buscar sus huellas en las tierras remotas. El viajero habla de los pueblos que vivieron en estos lugares y menciona a su poderoso caudillo. También reflexiona sobre la Ruta de la Seda y el gran mito creado en torno a ella, mito probablemente exagerado hasta tal punto que Luce Boulnois, reflexionando sobre esta ruta, se preguntaba: "¿se trata verdaderamente de una realidad concreta?" (Boulnois, 2004: 9). De alguna forma, Silvestre responde a esta cuestión:

Porque la Ruta de la Seda es una bella leyenda y, como todas las leyendas, pura idealización. Otro mito. No hay tal ruta. No la hubo nunca. Ese exitoso nombre solo identificaba un difuso entramado de caminos, redes de comunicación, afluentes, deltas y dédalos de comercio y contrabando que enlazaban los distintos y alejados territorios de Oriente y Occidente... (Silvestre, 2013: 205).

No obstante, aunque personalmente se muestre tan escéptico con esta visión idealizada de la Ruta de la Seda, recorre sus caminos, siguiendo las huellas de un misterioso viajero que estuvo allí antes que él:

...Y también un poderoso reino. El de Timor, el Gran Tamerlán, quien en menos de diez años se hizo con Irán, Irak, Siria y la zona este de Turquía. Yo estaba en su capital como centurias antes había estado otro español cuyo fantasma quería encontrar (Silvestre, 2013: 209).

La sospecha de que ese "otro español", cuyo "fantasma" persigue Silvestre, sea justamente el embajador medieval más famoso ante 
Tamorlán se confirma en el capítulo siguiente de su obra, que lleva por título "González de Clavijo". Silvestre deja muy claro que el objetivo de llegar a Samarcanda ha sido buscar los vestigios de la mítica embajada medieval:

Mi interés por las lecciones históricas sobre la gran corte y sus monumentos es escaso. [...] Sólo me preocupa una cosa muy concreta. [...] Busco las huellas de un embajador español que vino aquí en el siglo XV (Silvestre, 2013: 211).

El motero no está convencido de los conocimientos de los uzbecos actuales sobre este acontecimiento. Por esta razón le asombra que el joven guía con el que ha topado sepa dónde quedan rastros de Clavijo en Samarcanda y pueda llevarlo hacia allí. Cuando llegan a la placa con el nombre del embajador medieval al viajero le emociona lo que ve:

Es cierto, Clavijo, Klavixo para los uzbecos, tiene un recuerdo en Samarcanda. Es modesta, sucia y polvorienta. Pero ahí está, es un trozo de España en Uzbekistán (Silvestre, 2013: 213).

Al final del capítulo dedicado al embajador, el autor resume el viaje realizado por Clavijo anteponiendo al rigor histórico el afán por difundir el acontecimiento y darlo a conocer a un público más amplio.

Silvestre cumple su objetivo de encontrar los rastros del pasado en el presente de la ciudad de Samarcanda. No obstante, aunque el autor afirma seguir en su viaje las huellas de Clavijo, resulta que la alusión al viajero medieval y su embajada es mínima y aparece solo en la parte dedicada a la visita del motero a Samarcanda. En ningún otro momento de su relato el autor habla de su antecesor medieval, ni de su misión, ni compara su trayecto con la de los embajadores de antaño.

\section{Conclusiones}

El misterioso Oriente y, junto con él, la Ruta de la Seda que -recorrida y testimoniada por los escasos viajeros que siguieron su senda- fascinó al hombre del Medievo también hoy en día siguen presentes en el imaginario colectivo. Por esta razón, los autores contemporáneos vuelven la vista hacia los grandes relatos de viajes, como el de la Embajada. No obstante, los textos que construyen y el uso que le dan al original 
medieval no son los mismos. Mientras que en la novela histórica de Martínez Laínez, a pesar de la aparición de las características claramente contemporáneas, destaca un esfuerzo por rescatar los elementos esenciales de la poética del viaje medieval, el texto de Silvestre no guarda ninguna relación con su gramática interna ni con su retórica; no la imita, pero tampoco la comenta y ni siquiera la cuestiona. En el caso de Martínez Laínez podemos hablar del intento de seguir la escritura y la experiencia medieval, ya que el autor intenta hacerle creer al lector que se ha trasladado al mundo medieval. Por el contrario, el relato de Miguel Silvestre, dado su carácter del testimonio verídico, es inevitablemente contemporáneo y parece que lo que pretende el autor es utilizar la historia de Clavijo como un mero telón del fondo para situar su propia aventura en el contexto de los grandes viajeros medievales y hacerla así superior o más trascendente.

En esta tesitura nace la pregunta en torno al porqué de este interés por la recuperación de los viajeros medievales en las obras contemporáneas del género. ¿Se trata de un homenaje a los personajes históricos olvidados, de una manera de conectar con un tipo de viaje totalmente distinto al contemporáneo, o tal vez es una cuestión de marketing, de tratar de entrar en el mundo editorial -en el mundo de la Literatura con mayúsculas- siendo escritor no profesional? ¿O acaso será una combinación de ambos factores? ¿De qué forma esta tendencia se evidencia en la literatura actual? ¿Qué tipo de autores recurre a este procedimiento, de qué ámbitos proceden y qué relaciones tienen con la literatura y la historia?

Estos interrogantes sin respuestas unívocas ponen en evidencia la necesidad de seguir explorando en la poética del relato de viajes, desde la Antigüedad hasta nuestros días, por encima de encuadramientos históricos y geográficos; la necesidad de acercarse a los textos de viajes de distintas épocas y profundizar en los hilos de posibles interacciones, imitaciones, diálogos e intertextualidades que siguen tejiéndose entre ellos. No obstante, todas estas preguntas también dejan ver que, más que darle la razón a Silvestre, podríamos estar de acuerdo con el editor de la reciente y magna Silk Road Encyclopedia, Jeaon Su-Il, cuando defiende que:

La Ruta de la Seda no es un camino antiguo y ya muerto que ha sido cubierto por el desierto, los prados y océanos; es una senda activa y 
vibrante que conecta el ayer con el hoy en el curso de la historia de la humanidad (2016: 6) ${ }^{12}$.

\section{Bibliografía}

Alba Sanz, Ramón (ed.). 1984. Embajada a Tamerlán. Madrid: Miraguano Ediciones.

Alburquerque García, Luis. 2011. El "relato de viajes": hitos y formas en la evolución del género. Revista de Literatura 73: 15-34.

Alburquerque García, Luis. 2015. "Relatos de viaje" y paradigmas culturales. Letras 71: 63-76.

Almarcegui, Patricia. 2013. El sentido del viaje. Salamanca: Junta de Castilla y León.

Almarcegui, Patricia. 2016. Una viajera por Asia Central. Lo que queda de mundo. Barcelona: Edicions de la Universitat de Barcelona.

Béguelin-Argimón, Victoria. 2011. La geografía en los relatos de viajes castellanos del ocaso de la Edad Media. Análisis del discurso y léxico. Lausanne: Hispania-Helvética.

Beltrán, Rafael. 1991. Los libros de viajes medievales castellanos. Revista de Filología Románica, anejo 1: 121-164.

Boulnois, Luce. 2004. La Ruta de la Seda: dioses, guerreros y mercaderes. Barcelona: Península.

Carrizo Rueda, Sofía. 1997. Poética del relato de viajes. Kassel: Edition Reichenberger.

De Bunes Ibarra, Miguel Ángel. 2013. La ruta de la seda. Entre lo imaginario y lo real. En Ruiz Gutiérrez, Ana \& Sorroche Cuerva, Miguel Ángel (coord.) La ruta de la seda: camino de caminos. Granada: Editorial Universidad de Granada, 11-28.

Gil, Juan. 1993. En demanda del Gran Kan. Viajes a Mongolia en el siglo XIII. Madrid: Alianza Editorial.

Höllmann, Thomas O. 2015. La Ruta de la Seda. Madrid: Alianza Editorial. Huertas Morales, Antonio. 2012. La Edad Media contemporánea. Estudio de la novela española de tema medieval (1990-2012) (Tesis Doctoral). Valencia: Universitat de València-Departamento de Filología Española. [Base de datos Roderic]. http://roderic.uv.es/bitstream/handle/10550/27937/TESIS-ANTONIO\%20HUERTAS.pdf?sequence $=1$ López Estrada, Francisco (ed.). 1999. Embajada a Tamorlán, Madrid: Castalia.

\footnotetext{
${ }^{12}$ En el original: "The Silk Road is not a dead and ancient path that has since been covered by desert, meadows, and oceans; it is an active and vibrant pathway that connects yesterday with today in the course of human history" (la traducción es mía).
} 
López Estrada, Francisco. 2003. Libros de viajeros hispánicos medievales. Madrid: Ediciones del Laberinto.

López Estrada, Francisco. 2004. Un viaje medieval: Ruy González Clavijo visita Samarcanda y vuelve para contarlo. Revista de Occidente 280: $27-47$

López Estrada, Francisco. 2005. Ruy González de Clavijo. La embajada a Tamorlán. Relato del viaje hasta Samarcanda y regreso (1403-1406). Arbor 711-712: 515-535.

López Guzmán, Rafael. 2013. La embajada de Ruy González de Clavijo ante Tamerlán. En Ruiz Gutiérrez, Ana \& Sorroche Cuerva, Miguel Ángel (coord.) La ruta de la seda: camino de caminos. Granada: Editorial Universidad de Granada, 57-88.

Martínez de Campos, Carlos 2000. Caballos alados de la ruta de la seda. Madrid: Dossat.

Martínez Laínez, Fernando. 2003. Embajada a Samarcanda. Barcelona: Belacqua.

Ollivier, Bernard. 2005. La ruta de la seda. Viaje en solitario. Barcelona: Entrelibros.

Peñate Rivero, Julio. 2015. La poética del relato de viaje entre La Edad Media y el siglo XXI. Letras 71: 41-62.

Pérez Priego, Miguel Ángel. 1984. Estudio literario de los libros de viajes medievales. Epos 1: 217-239.

Rodríguez Zahar, León. 2013. Samarkanda. El sueño de Tamerlán. En Ruiz Gutiérrez, Ana \& Sorroche Cuerva, Miguel Ángel (coord.) La ruta de la seda: camino de caminos. Granada: Universidad de Granada, 29-56.

Rubio Tovar, Joaquín. 1986. Libros españoles de viajes medievales. Madrid: Taurus.

Silvestre, Miguel. 2013. La emoción del nómada. Barcelona: Comanegra.

Silvestre, Miguel. 2016. Nómada en Samarcanda. Madrid: Silver Rider Prodaktions.

Strubell, Pablo. 2009. Te odio, Marco Polo. Barcelona: Niberta.

Su-Il, Jeong. 2016. The Silk Road Encyclopedia. Gyeoangsangbuk-do Province: Korea Institute of Civilizational Exchanges.

Wood, Frances.1997. Did Marco Polo Go to China? Nueva York: Perseus.

Zygmunt, Karolina. 2016. El descubrimiento de la fauna exótica en los relatos de viajes: de las descripciones medievales a las imitaciones en la novela histórica contemporánea. Lectura y signo 11: 59-81. 